AperTO - Archivio Istituzionale Open Access dell'Università di Torino

Rare earth ions doped ZnO: Synthesis, characterization and preliminary photoactivity assessment

This is a pre print version of the following article:

Original Citation:

Availability:

This version is available http://hdl.handle.net/2318/1689463

since 2021-03-09T14:52:36Z

Published version:

DOI:10.1016/j.jssc.2018.05.001

Terms of use:

Open Access

Anyone can freely access the full text of works made available as "Open Access". Works made available under a Creative Commons license can be used according to the terms and conditions of said license. Use of all other works requires consent of the right holder (author or publisher) if not exempted from copyright protection by the applicable law. 


\title{
Rare Earth lons doped ZnO: Synthesis, Characterization and Preliminary Photoactivity Assessment
}

Erik Cerrato, Chiara Gionco, Ilaria Berruti, Fabrizio Sordello, Paola Calza, Maria Cristina Paganini*

Department of Chemistry and NIS (Interdipartimental Centre), via Giuria 7, 10125 Torino, Italy

Corresponding author: Maria Cristina Paganini, Department of Chemistry and NIS, via Giuria 7, 10125

Torino, tel +390116707576, email: mariacristina.paganini@unito.it

Keywords: ZnO, Rare Earth Doping, Photocatalysts

\begin{abstract}
This work reports the effect of doping zinc oxide with lanthanide ions on structural, EPR and UV visible properties. Bare and doped samples were synthesized using the simple and green hydrothermal process. Different rare earth ions ( $\mathrm{RE}=\mathrm{La}, \mathrm{Ce}, \mathrm{Pr}, \mathrm{Er}$ and $\mathrm{Yb}$ ) with $1 \%$ molar ratio $\mathrm{RE} / \mathrm{Zn}$ were used. The samples have been studied using X Ray Diffraction, Scanning Electron Microscopy (SEM), Transmission Electron Microscopy (TEM) and UV visible diffuse reflectance spectroscopy. Finally, electron paramagnetic resonance (EPR) spectroscopy, was used to assess the materials photoactivity under UV irradiation, both in solid state, to see the charge carriers' generation and in solution, evaluating the $\mathrm{OH} \bullet \mathrm{radi}$ cal formation using the DMPO (5,5-Dimethyl-1-Pyrroline-N-Oxide) spin trapping technique. The results suggest that the synthesized materials could be interesting systems for the photocatalytic abatement of emerging organic persistent pollutants in wastewater treatment plants.
\end{abstract}

\section{Introduction}

Recently, implementation of water remediation and re-use is gaining attention rapidly world-wide due to the water scarcity occurred as a result of climate change and poor water resource management (i.e. limited access to clean water resources and water demands exceed the available resources). Access to clean water is becoming an increasing problem in an expanding global economy and population countries. [1] Persistent organic pollutants and the new emerging pollutants are considered dangerous for living organisms due to their acute toxicity and bio-recalcitrant nature, in fact they are resistant to environment degradation and have been continuously released into the environment.[2,3] In particular, 
the biological process is usually ineffective because of a self-inhibitory effect on the microorganisms in the presence of these compounds. [4] For this reason, photocatalytic treatment represents an advanced oxidation technology able to remove organic pollutants thanks to the efficient degradation rate and high mineralization efficiency that leads to $\mathrm{CO}_{2}, \mathrm{H}_{2} \mathrm{O}$, and other minerals as final products. Among various semiconductor materials, $\mathrm{ZnO}$ has received considerable scientific interest as an alternative to $\mathrm{TiO}_{2}[5,6]$. It was also reported by some of us that $\mathrm{ZnO}$ was more efficient than $\mathrm{TiO}_{2}$ in photocatalytic degradation of some emerging pollutants in aqueous solution[7]

$\mathrm{ZnO}$ is considered as a benchmark catalyst due to its non-toxic nature, physical and chemical stability coupled with its low cost. [8] One major drawback of existing technology is the low quantum efficiency of $\mathrm{ZnO}$, which is due to very fast recombination of photogenerated electron-hole pairs. In order to improve the photocatalytic activity of $\mathrm{ZnO}$, several modification methods have been developed. It has been reported that photocatalytic performance of semiconductors can be improved by doping with certain cations, which can act as electron trapping agent to decrease the electron-hole recombination rate. $[9,10,11]$ The photocatalytic activity of $\mathrm{ZnO}$ can be significantly enhanced by doping with the lanthanide ions having $4 \mathrm{f}$ configuration, among them, cerium-doped $\mathrm{ZnO}$ nanomaterials exhibited versatile properties and much attention has been focused to explore them for possible applications in various technologies. $[12,13]$ Doping RE ions into ZnO produces a significant improvement in the charge separation between photogenerated electrons and holes. [14-16] The efficiency of cerium-doped ZnO towards degradation of water pollutants and emerging contaminants is already well known: phenol, iodinated $X$ ray contrast agents, namely iopamidol, iopromide and diatrizoate, emerging contaminants known to be scarcely abated in the wastewater treatment plants, and acesulfame $K$, an artificial sweetener, were efficiently abated. $[7,17]$ The role in the photoactivity of the forbitals, which in the case of cerium and lanthanum are empty and for the others lanthanides are partly filled, is still under debate. Moreover, the presence of lanthanide ions into the $\mathrm{ZnO}$ structure has never been demonstrated, thus the understanding of the role of the dopants in the host oxide is crucial.

In this work different materials based on ZnO doped with a low amount of RE elements (RE = La, Ce, Pr, Er and $\mathrm{Yb}$ ), aimed to develop new photocatalysts, were synthesized. Pure and doped ZnO with low RE loading ( $1 \%$ molar) were prepared via hydrothermal process, a simple and green way to obtain controlled nanostructures at relatively low temperatures. Compared with other techniques this method is fast, cheap and highly efficient. The precursors used are easily available on the market and the amount 
of rare earth compound employed is very low and does not affect dramatically the final price of the catalyst. The morphological and textural features, the crystal structure and optical properties of the synthesized materials were investigated and their photoactivity was assessed by EPR spectroscopy. The use of a spin probe molecule like DMPO (5,5-Dimethyl-1-Pyrroline-N-Oxide) allowed the evaluation of oxidant species present in solution.

\section{Experimental}

\subsection{Sample preparation}

All reactants employed in this work were purchased from Sigma-Aldrich (Milan Italy) and used without any further purification treatment. All the samples have been synthesized following hydrothermal synthesis. Bare $\mathrm{ZnO}$ sample was synthesized starting from a $1 \mathrm{M}$ water solution of zinc nitrate. Then a $4 \mathrm{M}$ $\mathrm{NaOH}$ solution was added dropwise until the $\mathrm{pH}$ was 11 . Finally, the solution was transferred into a PTFE-lined stainless steel $100 \mathrm{~mL}$ autoclave (filling 70\%), and treated at $175^{\circ} \mathrm{C}$ for 15 hours. The product was centrifuged, washed three times and dried at $70^{\circ} \mathrm{C}$ overnight. The doped samples (RE=Ce, $\mathrm{La}, \mathrm{Er}$, $\mathrm{Yb}, \mathrm{Pr}$, molar concentration $1 \%$ ) were prepared adding to the starting solution the RE precursor salts in stoichiometric amount $\left(\operatorname{RE}\left(\mathrm{NO}_{3}\right)_{3} \mathrm{xH}_{2} \mathrm{O}, \mathrm{x}=5\right.$ or 6 depending on the RE). Hereafter the doped samples will be labelled as ZnO-RE.

\subsection{Characterization techniques}

X-rays powder diffraction (XRPD) patterns were recorded using a PANalytical PW3040/60 X'Pert PRO MPD, Lissone (MI) Italy $(45 \mathrm{kV}, 40 \mathrm{~mA})$ with a copper $\mathrm{K} \alpha$ radiation source $(0.15418 \mathrm{~nm})$. Samples were scanned continuously in the $2 \theta$ range between $10^{\circ}$ and $100^{\circ}$. The $X^{\prime}$ Pert High-Score software was used to identify the mineral phases present in the samples. A Rietveld refinement was performed on the acquired patterns using the MAUD 2.2 software[18].

The morphology of the materials was studied by scanning electron microscopy (SEM) using a JEOL microscope (JSM-6510-LV, JEOL, Tokyo, Japan) and by a transmission electron microscopy (TEM) using a Jeol JEM 3010 (300 kV) microscope.

The UV-Vis absorption spectra were recorded using a Varian Cary 5000 spectrophotometer, coupled with an integration sphere for diffuse reflectance studies (DRS), using a Carywin-UV/scan software. A sample of PTFE with $100 \%$ reflectance was used as reference. 
Electron Paramagnetic Resonance Spectroscopy (EPR) was employed, using an X-band CW-EPR Bruker EMX spectrometer equipped with a cylindrical cavity operating at $100 \mathrm{KHz}$ field modulation. The effect of UV light on EPR spectra was investigated using a $1600 \mathrm{~W}$ Xenon lamp (Oriel Instruments) equipped with an IR water filter. The samples were treated before the measurement as follows: first, the sample was heated under vacuum at $300^{\circ} \mathrm{C}$ for 30 minutes, then heated under oxygen pressure $(50 \mathrm{mbar})$ at $500^{\circ} \mathrm{C}$ for 1 hour. The formation of $\mathrm{OH}^{\bullet}$ radical species upon irradiation (500 W, Xenon lamp, Oriel Instruments) was monitored by EPR spin trapping technique using a Miniscope 100 spectrometer from Magnettech and using DMPO (5,5-dimethyl1-pyrroline-N-oxide) as spin trapping agent.

\section{Results and Discussion}

\subsection{Structural, Morphological and Spectroscopic characterization}

XRPD patterns of the samples investigated in this work are shown in Fig.1. The pattern of bare ZnO

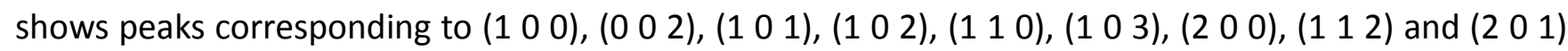
planes of the wurtzite hexagonal phase of ZnO [19].

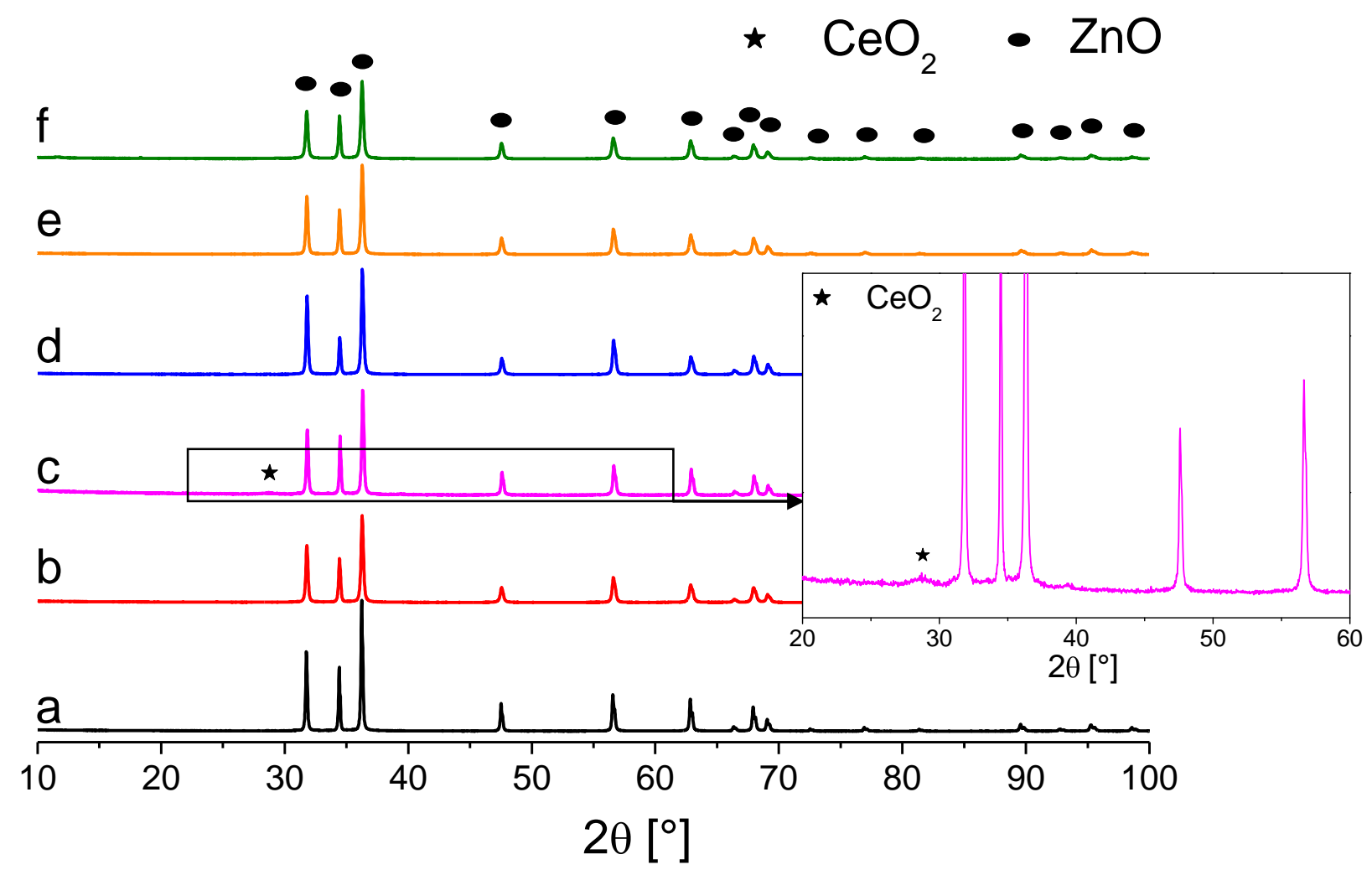


Figure 1. XRD patterns of a) ZnO, b) ZnO-La, c) ZnO-Ce, d) ZnO-Pr, e) ZnO-Er, f) ZnO-Yb. Inset: enlargement of the $\mathrm{ZnO}-$ Ce pattern.

The introduction of dopants does not bring relevant modifications in the diffraction patterns of ZnO with the exception of the sample $\mathrm{ZnO}-\mathrm{Ce}$ in which we observed the formation of a tiny amount of the $\mathrm{CeO}_{2}$ crystalline phase (see Fig. 1, inset). On the XRD patterns we performed a Rietveld refinement using the MAUD software[18]. Table 1 lists the obtained average crystallite size and the lattice parameters for all the detected phases. Moreover, the difference in the lattice parameters ( $a$ and $c$ ) due to the addition of lanthanides ions inside the $\mathrm{ZnO}$ structure is also evidenced $(\Delta a / c=a / c(\mathrm{ZnO}-\mathrm{RE})-a / c(\mathrm{ZnO}))$. The lattice parameters of the $\mathrm{ZnO}$ phase are slightly influenced by the introduction of lanthanides, bringing to a limited contraction of the unit cell for all the doped samples respect to that of pure $\mathrm{ZnO}$. The average crystallite size of bare zinc oxide is quite large $(d=256 \mathrm{~nm})$, the insertion of RE ions in the structure causes in general a decrease in the average crystallite size, the sample $\mathrm{ZnO}-\mathrm{Yb}$ being the mostly affected, while the sample Ce-ZnO is the less affected, probably because of the formation of the cerium oxide phase. This effect is due to the insertion of the foreign atoms in the structure, that limits the crystallite growth.

Table 1. Cell parameters and crystallite size obtained from Rietveld refinement of the XRD patterns of bare and doped $\mathrm{ZnO}$. The difference between the parameters of the doped samples and the bare $\mathrm{ZnO}$ are also evidenced as $\Delta$.

\begin{tabular}{cccccccc} 
Sample & Phase & $a(\AA)$ & $\Delta a$ & $c(\AA)$ & $\Delta c$ & $d(\mathrm{~nm})$ & $\Delta d$ \\
\hline ZnO & ZnO & 3,2554 & 0,0000 & 5,2143 & 0,0000 & 256 & 0 \\
ZnO-La & $\mathrm{ZnO}$ & 3,2528 & $-0,0026$ & 5,2125 & $-0,0018$ & 124 & -132 \\
ZnO-Ce & $\mathrm{ZnO}$ & 3,2528 & $-0,0026$ & 5,2111 & $-0,0032$ & 163 & -93 \\
& $\mathrm{CeO}_{2}$ & 5,4111 & & & & 10 & \\
ZnO-Pr & $\mathrm{ZnO}$ & 3,2529 & $-0,0026$ & 5,2125 & $-0,0018$ & 139 & -117 \\
ZnO-Er & $\mathrm{ZnO}$ & 3,2529 & $-0,0025$ & 5,2123 & $-0,0020$ & 127 & -129 \\
ZnO-Yb & $\mathrm{ZnO}$ & 3,2536 & $-0,0019$ & 5,2122 & $-0,0021$ & 93 & -163 \\
\hline
\end{tabular}



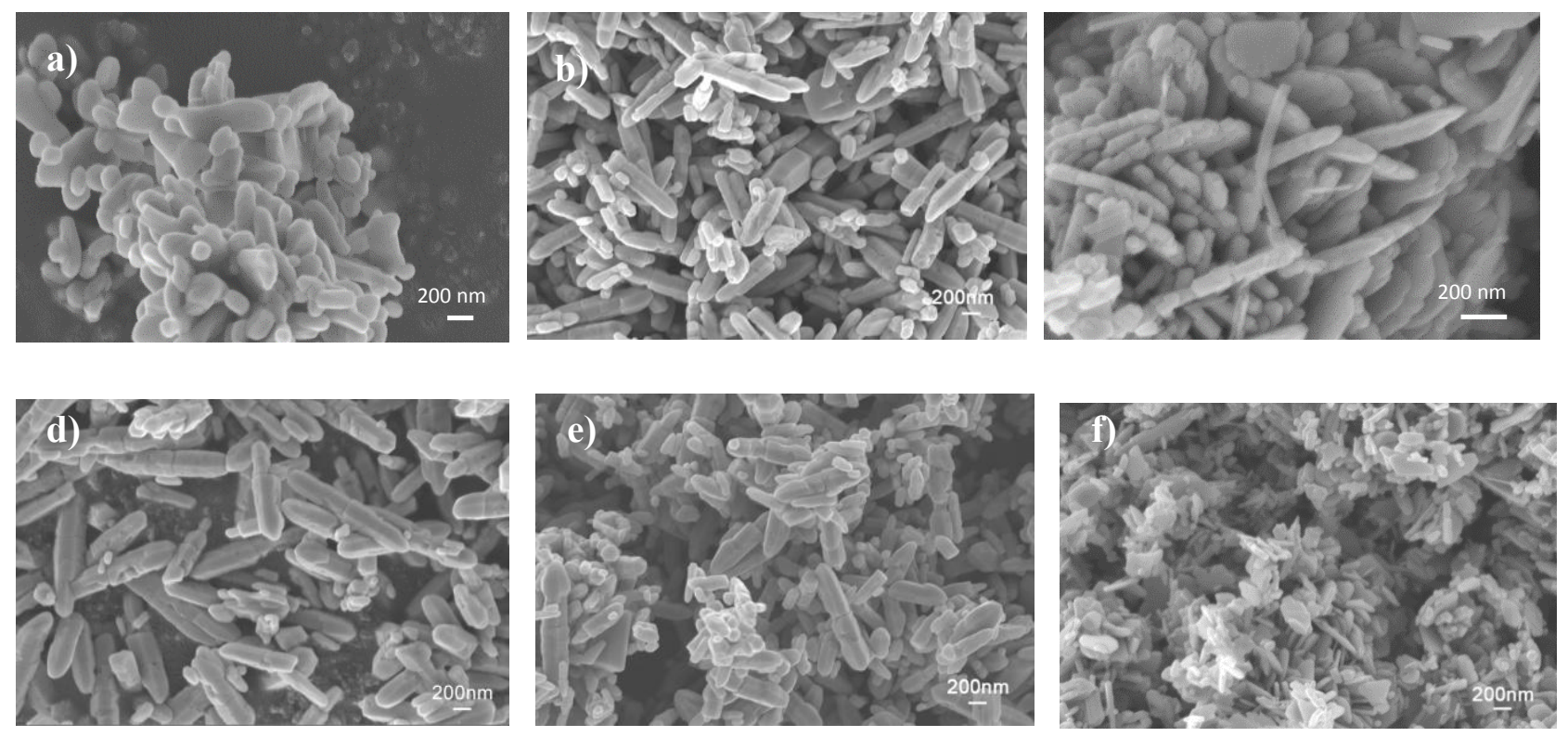

Figure 2: SEM micrographs of a) ZnO, b) ZnO-La, c) ZnO-Ce, d) ZnO-Pr, e) ZnO-Er, f) ZnO-Yb.

Figure 2 depicts the surface morphology of pure (a) and doped (b-f) ZnO catalysts. The surface of all the samples, with the only exception for $\mathrm{ZnO}-\mathrm{Yb}$, exhibits similar morphology: rods with 1.0-1.5 $\mu \mathrm{m}$ of length are randomly oriented and aggregated. The sample doped with $\mathrm{Yb}$ (Fig. 2f) exhibits an intermediate shape between platelets and rods with smaller particles as already revealed by the Rietveld refinement.

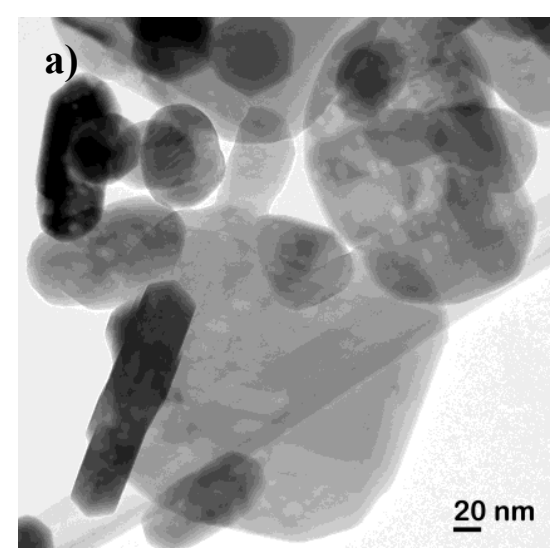

d)
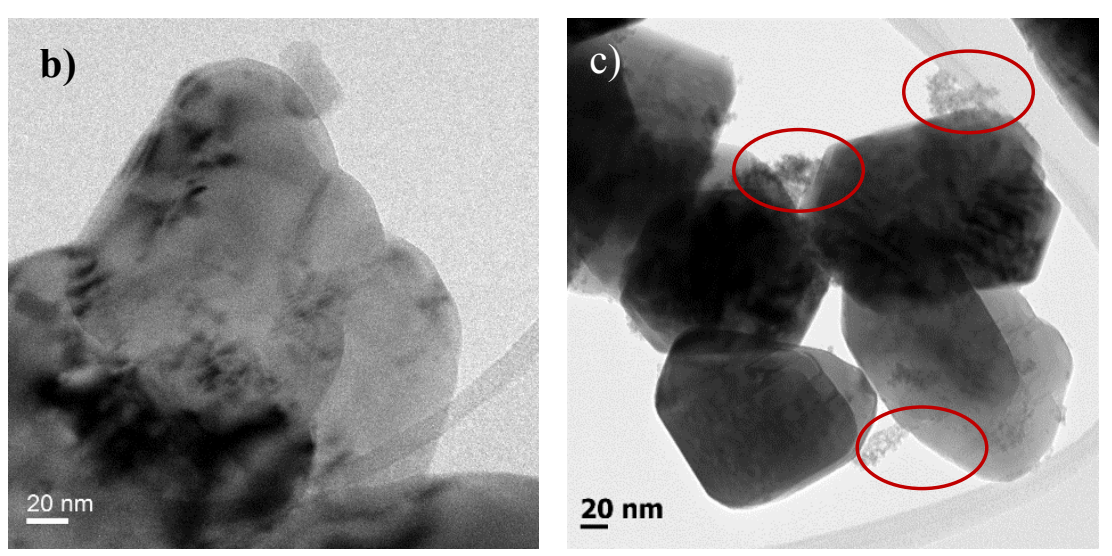

e) 

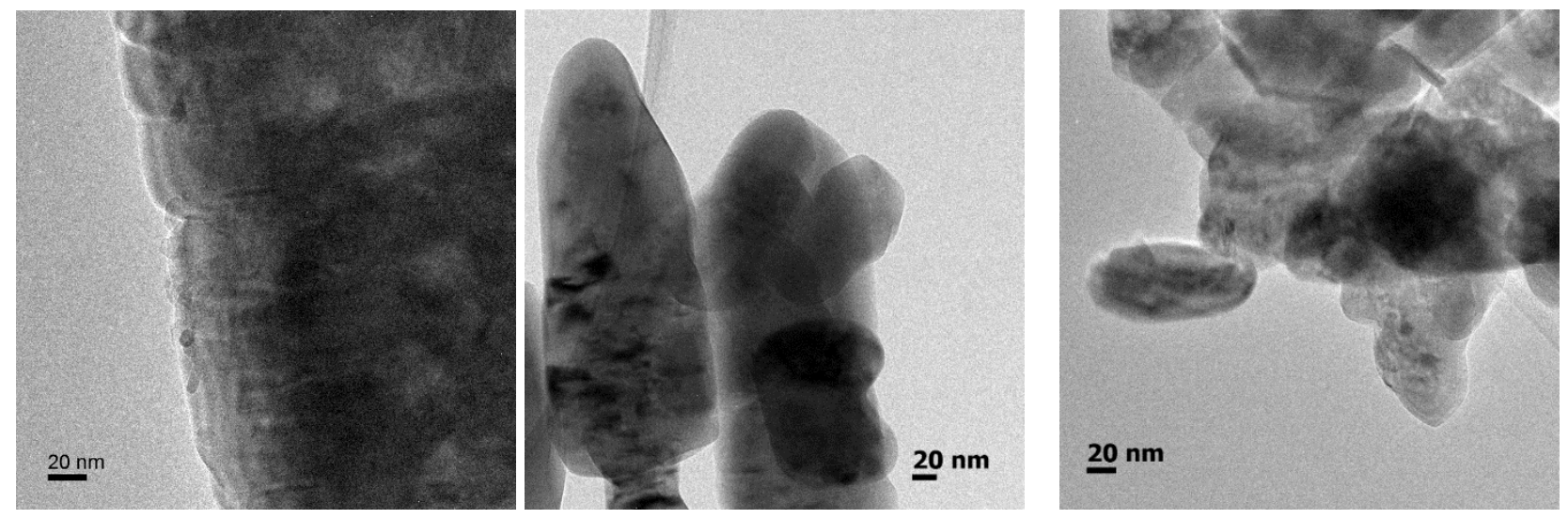

Figure 3. TEM micrographs of a) ZnO, b) ZnO-La, c) ZnO-Ce, d) ZnO-Pr, e) ZnO-Er, f) ZnO-Yb

Figure 3 reports TEM micrographs of $\mathrm{ZnO}$ and doped materials. Only in the case of cerium doped materials (Fig. 3b) is possible to observe clearly small particles anchored at the surface of ZnO platelet (highlighted with red circles). This observation is in agreement with the presence of $\mathrm{CeO}_{2}$ (Ce oxidation state: +4 ) diffraction peaks in the XRPD analysis and it is further confirmed by the previously reported elemental EDS mapping that shows the Ce confinement [17]. Lanthanum, praseodymium and erbium are all stable as $\mathrm{Ln}^{3+}$ ions, and the ionic radii of the first two are quite larger than that of $\mathrm{Zn}^{2+}$. The micrographs related to these dopants reveal a morphology that is close to that of pure $\mathrm{ZnO}$, and it's not possible to see evidence of other phases except to some shadows that can be related to both $\mathrm{ZnO}$ defects and/or XRD silent amorphous phases. ZnO-Yb micrographs point out the presence of smaller particles, that could be correlated to the large decrease of the crystallite size (see table 1). Yb ions can be stable also with oxidation number +2 (isovalent with $\mathrm{Zn}^{2+}$ ions), moreover they are the smallest ions among all the dopants series, thus their insertion in the $\mathrm{ZnO}$ matrix is possible and likely.

The influence of RE doping on the optical absorption of the various samples has been investigated with Diffuse Reflectance (DR) UV-Vis spectroscopy. Figure 4 compares the spectra recorded for pure zinc with those of the variously doped samples. The spectrum of bare $\mathrm{ZnO}$ is well known and it is dominated by the band gap transition occurring at about $400 \mathrm{~nm}(3.3 \mathrm{eV})$ that is due to the electrons excitation from the valence band (VB) to the conduction band (CB) [20]. The use of different types of dopant does not dramatically affects the band gap of the materials. Indeed we calculated the energy gap $\left(E_{g}\right)$ value for all the samples using the Tauc plot, i.e. by linearization of the plot reporting $(\alpha h v)^{2} v s h v$, typical of direct band gap transitions [21]. The values obtained are very similar for all samples, indicating that the RE insertion in the ZnO matrix does not affect directly the VB $\rightarrow$ CB transition of zinc oxide. 
Nevertheless, in the case of samples containing $\mathrm{Pr}, \mathrm{Er}$ and $\mathrm{Yb}$ it is possible to detect the presence of a multitude of defined absorption bands, related to the $\mathrm{f}-\mathrm{f}$ transitions of $\mathrm{Pr}, \mathrm{Er}$ and $\mathrm{Yb}$ ion states. The presence of these bands indicates that the RE ions are actually present in the samples (despite the other characterizations results) and well diluted in the matrix, preserving their optical properties [2224]. Finally, for all the doped samples except for $\mathrm{ZnO}-\mathrm{Yb}$, we observed a slight tail of absorption extending to the visible region (see Fig. 4, panel B), this effect is more evident for the ZnO-Ce sample. $\mathrm{ZnO}-\mathrm{Yb}$ sample presents a deep absorption in the NIR region. The intensity of this signal respect to the others suggests that for the other samples the nominal concentration was not achieved.
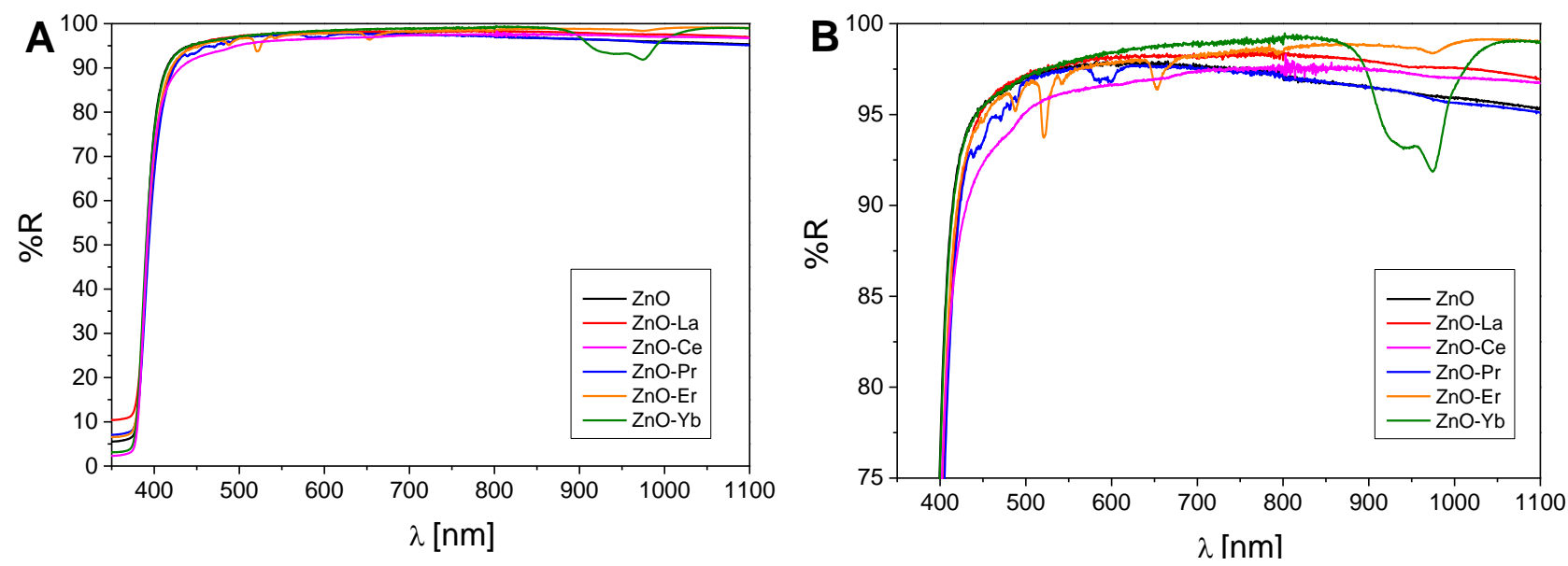

Figure 4. Percentage of Reflectance spectra of $\mathrm{ZnO}$ and RE doped $\mathrm{ZnO}$, Panel $\mathrm{B}$ is the enlargement of panel A.

\subsection{EPR spectroscopy}

In this work EPR spectroscopy was used to investigate the effect of UV light on the synthesized samples. This technique allows the assessment of the photoactivity of the samples, monitoring the charge carriers' separation under irradiation. All the spectra were recorded after activation of the samples as described in section 2.1.

Fig. 5 reports the EPR spectra before (Panel A) and during UV irradiation (Panel B), respectively. Panel A reveals that before irradiation, all samples are characterized by an isotropic signal at $g=2.014$, due to the synthesis procedure, and a broader and slightly asymmetric signal around $g=1.96$. The assignment for the signal at $\mathrm{g}=2.014$ is not straightforward, it was already reported in the past, without a clear identification. [25] The signal around $g=1.96$ has been extensively studied, and its assignment is still 
under debate: oxygen vacancies [26-30], zinc interstitial [27,31] and so interstitial hydrogen atoms acting as shallow donors. [32] Computational studies corroborate the hypothesis that this signal is generated by shallow donor species. $[33,34]$ The signal broadening that we observed in our spectra it is probably due to different environments felt by the unpaired electron [34, 35] indicating a certain degree of heterogeneity in the samples.
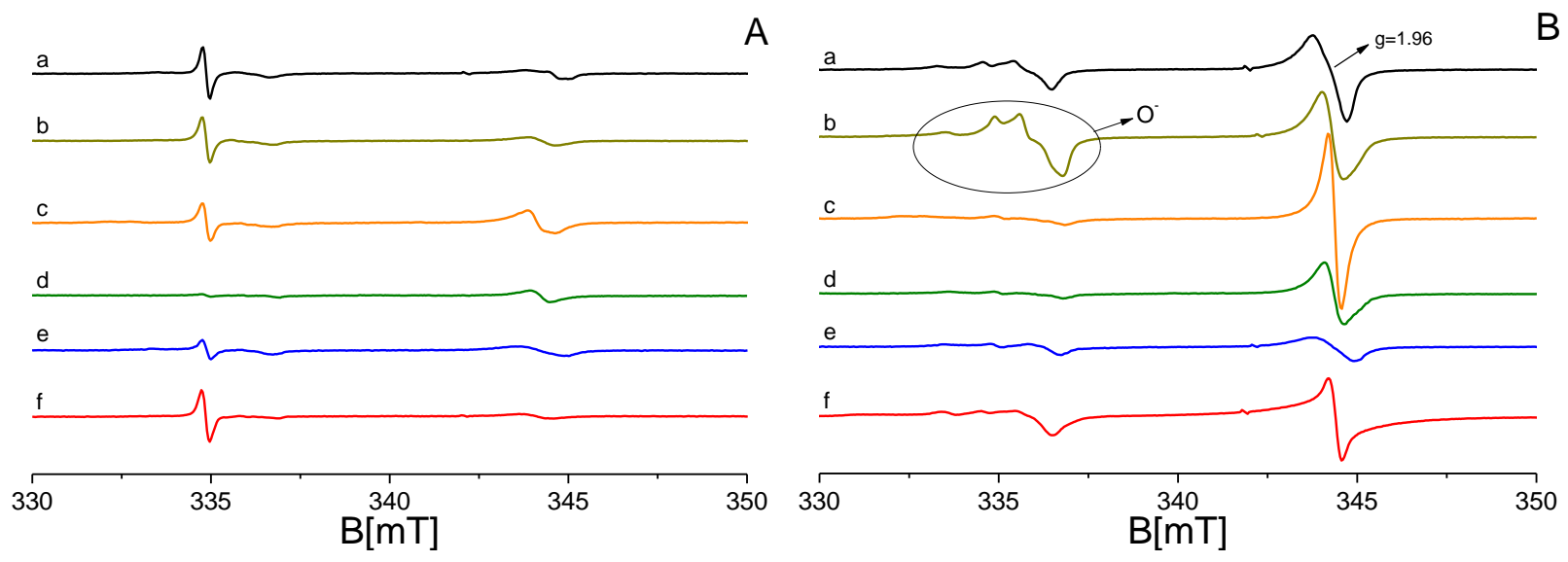

Figure 5. EPR spectra recorded at 77K of activated samples before (Panel A) and during (Panel B) UV irradiation: a) ZnO, b) ZnO-La, c) ZnO-Ce, d) ZnO-Pr, e) ZnO-Er, f) ZnO-Yb.

Figure 5 (panel B) reports the spectra obtained during UV irradiation. The absorption of photons allows the promotion of electrons from the valence band to the conduction band, with the consequent formation of holes in the valence band. [26] The photogenerated charge carriers can be stabilized at defect sites, forming paramagnetic species, thus EPR active.

For all samples, with different extent for the various dopants, the intensity of the signal at $g=1.96$ increases, indicating that irradiation probably formed trapped electronic species. The photogenerated holes are stabilized at $\mathrm{O}^{2-}$ sites, forming the well-known $\mathrm{O}^{-}$ions (as highlighted with a circle in Figure 5, panel B). [36, 37] This signal with $\mathrm{g}_{/ /}=2.023$ and $\mathrm{g}_{\perp}=2.003$ is formed mainly by the samples $\mathrm{ZnO}, \mathrm{ZnO}-\mathrm{La}$ and $\mathrm{ZnO}-\mathrm{Yb}$. These results indicate that the synthesized samples are active under irradiation, being capable of forming electron-hole pairs. Among all the synthesized materials ZnO-La showed the formation of higher signal due to the formation of holes and for this reason we decided to test its potential photocatalytic activity irradiating an aqueous suspension of the solid with the polychromatic light emitted by a Xe lamp and using DMPO (5,5-dimethyl-1-pyrrolineN-oxide) as spin-trapping agent to detect the formation of hydroxyl radicals $\left(\mathrm{OH}^{\circ}\right)$ in solution. For comparison the same experiment has been carried out also for the bare ZnO. The DMPO molecule (diamagnetic) forms a stable paramagnet- 
ic adduct with $\mathrm{OH}$ radicals $\left(\mathrm{DMPO} / \mathrm{OH}^{\circ}\right)$, detectable by the EPR technique [38]. The hydroxyl radicals are responsible for the oxidative degradation of organic molecules in photocatalytic reactions, and thus their detection is a good preliminary test for the potential photocatalytic activity. Hydroxyl radicals are formed under irradiation according to the following process:

$$
\mathrm{h}^{+}(\mathrm{VB})+\mathrm{H}_{2} \mathrm{O} \rightarrow \mathrm{HO}^{\bullet}+\mathrm{H}^{+}
$$
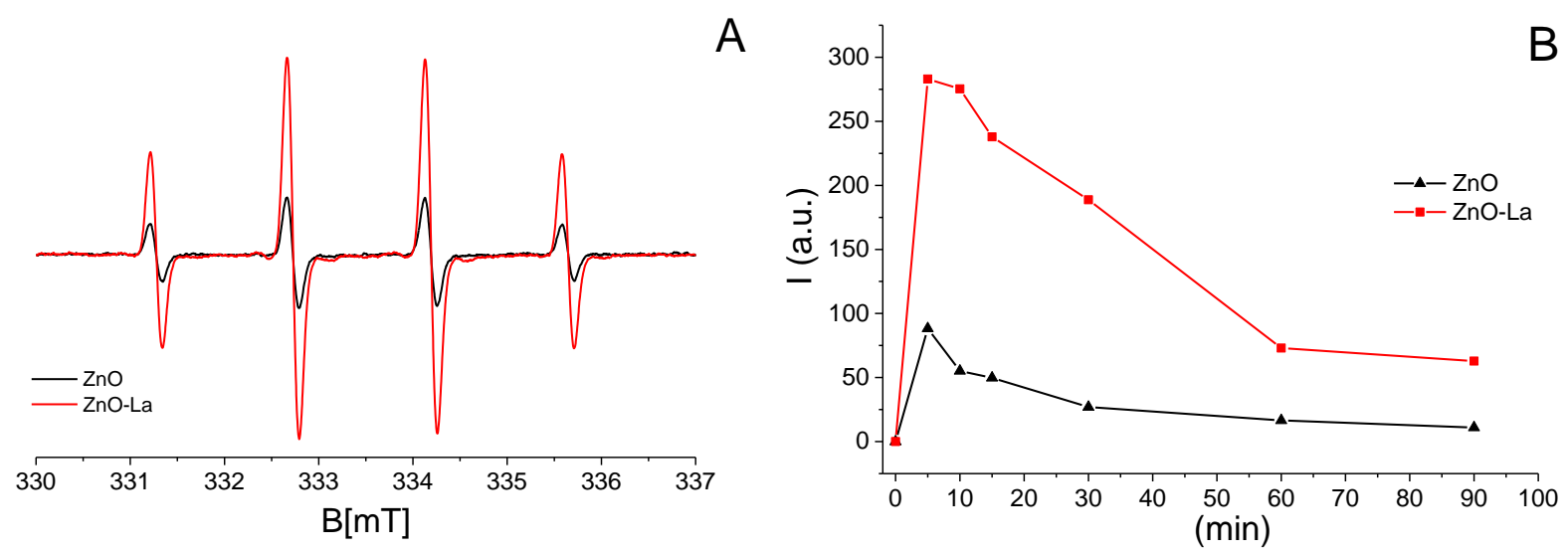

Figure 6. Panel (A): EPR spectra of the $\mathrm{DMPO} / \mathrm{OH}^{\bullet}$ adduct produced by irradiation of an aqueous suspension of the samples ZnO and ZnO-La with UV light for $5 \mathrm{~min}$; panel (B): integrated intensities of the EPR spectra as a function of irradiation time.

The aqueous suspension of bare $\mathrm{ZnO}$ forms $\mathrm{OH}$ radicals under UV irradiation, but the suspension with the doped sample exhibits signals that are three times more intense than the pure sample. Figure 6 (panel $(A)$ ) reports the classic four-lines EPR spectrum of the DMPO/OH ${ }^{\bullet}$ adduct, as observed after 5 min of irradiation for both samples. This irradiation time corresponds to the maximum intensity reached by the EPR spectra, meaning the higher amount of hydroxyl radicals formed. Panel (B) shows the integrated area values of the EPR spectra (which are proportional to the radical formation in solution) as a function of the irradiation time. The results show that the La-doped sample can generate hydroxyl radicals in solution when irradiated, with a higher efficiency compared with the bare oxide. The doped samples are thus good potential photocatalysts for the abatement of persistent emerging organic pollutants and will be the focus of a forthcoming paper.

\section{Conclusions}


Different photocatalysts based on ZnO and doped ZnO have been synthesized. The dopant used were all lanthanides: $\mathrm{La}, \mathrm{Ce}, \mathrm{Pr}, \mathrm{Er}$ and $\mathrm{Yb}$ with $1 \%$ molar of nominal amount. All the prepared materials were fully characterized via structural, morphological and spectroscopic techniques. Dopants behave differently according to their oxidation number and to the number of electrons in their f orbitals. Only cerium creates a new oxide phase, all the others are probably inserted in the $\mathrm{ZnO}$ matrix. Among all the prepared materials $\mathrm{ZnO}$-La, that showed the highest interaction with light at the solid state, has been chosen for the evaluation of $\mathrm{OH}$ radicals production in water suspension. The concentration of $\mathrm{OH}$ radicals has been evaluated using the spin trap molecule DMPO able to trap the $\mathrm{OH}^{\bullet}$ generated by the UV irradiation. The doped sample is three times more active under UV light than the bare ZnO, demonstrating that lanthanide-doped zinc oxide can be a promising system to consider in the photocatalytic abatement of organic pollutants.

\section{Acknowledgments}

We acknowledge support from a Marie Curie International Research Staff Exchange Scheme Fellowship (MAT4TREAT, proposal no. 645551) within the Horizon 2020 European Community Framework Programme and the Local Funding of the University of Torino call_2014_L2_126. We acknowledge support by MIUR, in the frame of the collaborative international consortium WATERJPI2013-MOTREM of the "Water Challenges for a Changing World" Joint Programming Initiative (WaterJPI) Pilot Call, and in the PRIN project "Solar driven chemistry: new materials for photo- and electro-catalysis (SMARTNESS)" 2015K7FZLH and financial support from European Union's Horizon 2020 research and innovation programme under the Marie Skłodowska-Curie grant agreement No 765860 - AQUAlity - H2020-MSCAITN-2017. A special thanks to Maria Carmen Valsania for the TEM images.

\section{References}

[1] C.B. Ong, L.Y. Ng, A.W. Mohammad, A review of ZnO nanoparticles as solar photocatalysts: Synthesis, mechanisms and applications, Renewable \& Sustainable Energy Reviews 81 (2018) 536-551.

[2] M. Sarro, N.P. Gule, E. Laurenti, R. Gamberini, M.C. Paganini, P.E. Mallon, P. Calza, ZnO-based materials and enzymes hybrid systems as highly efficient catalysts for recalcitrant pollutants abatement, Chemical Engineering Journal 334 (2018) 2530-2538.

[3] S. Ramachandran, A. Sivasamy, Nanocrystalline ZnO as a Visible Active Photocatalyst for the Degradation of Benzene1,4-diol, International Journal of Nanoscience 17(1-2) (2018).

[4] V. Vaiano, M. Matarangolo, O. Sacco, D. Sannino, Photocatalytic treatment of aqueous solutions at high dye concentration using praseodymium-doped ZnO catalysts, Applied Catalysis B-Environmental 209 (2017) 621-630.

[5] V. Vaiano, M. Matarangolo, J.J. Murcia, H. Rojas, J.A. Navio, M.C. Hidalgo, Enhanced photocatalytic removal of phenol from aqueous solutions using ZnO modified with Ag, Applied Catalysis B-Environmental 225 (2018) 197-206. 
[6] A. Umar, Y.B. Hahn, Metal Oxide Nanomaterials and Their Application, American Scientific Publiscers, Los Angeles, USA, 2010.

[7] P. Calza, C. Gionco, M. Giletta, M. Kalaboka, V.A. Sakkas, T. Albanis, M.C. Paganini, Assessment of the abatement of acelsulfame K using cerium doped ZnO as photocatalyst, Journal of Hazardous materials 323 (2016) 471-477.

[8] A.A. Ismail, A. El-Midany, E.A. Abdel-Aal, H. El-Shall, Application of statistical design to optimize the preparation of ZnO nanoparticles via hydrothermal technique, Mater. Lett. 59(14-15) (2005) 1924-1928.

[9] W. Zhang, Z. Zhong, Y. Wang, R. Xu, Doped solid solution: (Zn0.95Cu0.05) 1-xCdxS nanocrystals with high activity for H2 evolution from aqueous solutions under visible light, J. Phys. Chem. C 112(45) (2008) 17635-17642.

[10] J. Rodrigues, M.R.N. Soares, N.F. Santos, T. Holz, N. Ben Sedrine, C. Nico, A.J.S. Fernandes, A.J. Neves, F.M. Costa, T. Monteiro, Defect luminescence in oxide nanocrystals grown by laser assisted techniques, in: I.M. Tiginyanu (Ed.), Nanotechnology Vii2015.

[11] A. Blanca-Romero, J.M. Hernandez-Alcantara, M.A. Ocana-Bribiesca, J.F. Rivas-Silva, Study of high electronic correlation in ZnO:Eu, Revista Mexicana De Fisica 57(4) (2011) 338-343.

[12] B.G. Mishra, G.R. Rao, Promoting effect of $\mathrm{CeO}_{2}$ on cyclohexanol conversion over $\mathrm{CeO}_{2}-\mathrm{ZnO}$ mixed oxide materials prepared by amorphous citrate process, Bull. Mater. Sci. 25 (2002) 155-162.

[13] M.T. Wang, L. Fang, M. Li, Z.G. Liu, Y.H. Hu, X.W. Zhang, Effect of Rare Earth Dopant on Thermal Stability and Structure of ZnO-B2O3-SiO2 Glass, Journal of Inorganic Materials 32(6) (2017) 643-648.

[14] N. Yao, J. Huang, K. Fu, S. Liu, E. Dong, Y. Wang, X. Xu, M. Zhu, B. Cao, Efficiency enhancement in dye-sensitized solar cells with down conversion material ZnO: Eu3+, Dy3+, J Power Sources 267 (2014) 405-410.

[15] M. Faisal, A.A. Ismail, A.A. Ibrahim, H. Bouzid, S.A. Al-Sayari, Highly efficient photocatalyst based on Ce doped ZnO nanorods: Controllable synthesis and enhanced photocatalytic activity, Chem. Eng. J. 229 (2013) 225-233.

[16] P.V. Korake, R.S. Dhabbe, A.N. Kadam, Y.B. Gaikwad, K.M. Garadkar, Highly active lanthanum doped ZnO nanorods for photodegradation of metasystox, J. Photochem. Photobiol. B Biol. 130 (2014) 11-19.

[17] M.C. Paganini, D. Dalmasso, C. Gionco, V. Polliotto, L. Mantilleri, P. Calza, Beyond TiO2: Cerium-Doped Zinc Oxide as a New Photocatalyst for the Photodegradation of Persistent Pollutants, ChemistrySelect 1(12) (2016) 3377-3383.

[18] L. Lutterotti, Nucl. Instrum. Methods Phys. Res., Sect. B 268 (2010) 334-340.

[19] O. Bechambi, A. Touati, S. Sayadi, W. Najjar, Effect of cerium doping on the textural, structural and optical properties of zinc oxide: Role of cerium and hydrogen peroxide to enhance the photocatalytic degradation of endocrine disrupting compounds, Mater. Sci. Semicond. Process. 39 (2015) 807-816.

[20] H. Qin, W. Li, Y. Xia, T. He, Photocatalytic activity of heterostructures based on ZnO and N-doped ZnO, ACS Appl. Mater. Interfaces 3(8) (2011) 3152-3156.

[21] G. Martra, E. Gianotti, S. Coluccia, The Application of UV - Visible - NIR Spectroscopy to Oxides, in: S.D. Jackson, J.S.J. Hargreaves (Eds.), Metal Oxide Catalysis, WILEY-VCH Verlag GmbH \& Co. KGaA, Weinheim2009, pp. 51-94.

[22] W.T. Carnall, Handbook on the Physics and Chemistry of Rare Earths, in: J.a.L.E. Karl A. Gschneidner (Ed.)1979, pp. 171208.

[23] W.T. Carnall, P.R. Fields, R. Sarup, Optical Absorption Spectra of Er3+:LaF3 and ErCl3 · 6H2O, J. Chem. Phys. 57(1) (1972) 43-51.

[24] J. Reszczyńska, T. Grzyb, J.W. Sobczak, W. Lisowski, M. Gazda, B. Ohtani, A. Zaleska, Visible light activity of rare earth metal doped (Er3+, Yb3+ or Er3+/Yb3+) titania photocatalysts, Appl. Catal., B 163 (2015) 40-49.

[25] J.H. Lunsford, J.P. Jayne, Electron Paramagnetic Resonance of Oxygen on ZnO and UltravioletIrradiated MgO J. Chem. Phys. 44(1487) (1966) 1487-1492.

[26] J.M. Smith, W.E. Vehse, ESR of electron irradiated ZnO confirmation of the $F^{+}$center, Phys. Lett. 31A (1970) $147-148$.

[27] F. Morazzoni, R. Scotti, S. Volontè, Electron Paramagnetic Resonance Investigation of Paramagnetic Point Defects in ZnO and ZnO-supported Ruthenium, J. Chem. Soc. Faraday Trans. (1990) 1587-1591.

[28] F.A. Selim, M.H. Weber, D. Solodovnikov, K.G. Lynn, Nature of native defects in ZnO, Phys. Rev. Lett. 99(8) (2007) 085502.

[29] M.D. McCluskey, S.J. Jokela, Defects in ZnO, J. Appl. Phys. 106(7) (2009) 071101.

[30] P.H. Kasai, Electron Spin Resonance Studies of Donors and Acceptors in ZnO, Phys. Rev. 130(3) (1963) $989-995$.

[31] S.B. Zhang, S.H. Wei, A. Zunger, Intrinsicn-type versusp-type doping asymmetry and the defect physics of ZnO, Phys. Rev. B 63(7) (2001).

[32] C.G.V.d. Walle, Hydrogen as a Cause of Doping in Zinc Oxide, Phys. Rev. Lett. 85 (2000) 1012-1015.

[33] C.G.V.d. Walle, Defect analysis and engineering in ZnO, Physica B 308-310 (2001) 899-903.

[34] A. Janotti, C.G.V.d. Walle, Native point defects in ZnO, Phys. Rev. B 76(16) (2007) 165202-1-165202-22.

[35] K.M. Sancier, ESR investigation of photodamage to Zinc Oxide Powders, Appl. Surf. Sci. 21 (1970) 1-11. 
[36] N.B. Wong, Y.B. Taarit, J.H. Lunsford, Formation of O- in ZnO from the dissociation of adsorbed N2O, J. Chem. Phys. 60(5) (1974) 2148-2151.

[37] A.M. Volodin, S.E. Malykhin, G.M. Zhidomirov, O- radical anions on oxide catalysts: Formation, properties, and reactions, Kinet. Catal. 52(4) (2011) 605-619.

[38] D. Dvoranová, V. Brezová, M. Mazúr, M.A. Malati, Investigations of metal-doped titanium dioxide photocatalysts Appl. Catal., B 37 (2002) 91-105. 